\title{
Effect of initial substrate conditions on growth of cubic silicon carbide
}

Remigijus Vasiliauskas, M. Marinova, Mikael Syväjärvi, Rickard Liljedahl, G. Zoulis,

J. Lorenzzi, G. Ferro, S. Juillaguet, J. Camassel, E. K. Polychroniadis and Rositsa Yakimova

\section{Linköping University Post Print}

N.B.: When citing this work, cite the original article.

Original Publication:

Remigijus Vasiliauskas, M. Marinova, Mikael Syväjärvi, Rickard Liljedahl, G. Zoulis, J. Lorenzzi, G. Ferro, S. Juillaguet, J. Camassel, E. K. Polychroniadis and Rositsa Yakimova, Effect of initial substrate conditions on growth of cubic silicon carbide, 2011, Journal of Crystal Growth, (324), 1, 7-14.

http://dx.doi.org/10.1016/j.jcrysgro.2011.03.024

Copyright: Elsevier http://www.elsevier.com/

Postprint available at: Linköping University Electronic Press http://urn.kb.se/resolve?urn=urn:nbn:se:liu:diva-69870 


\title{
Effect of initial substrate conditions on growth of cubic
}

\section{silicon carbide}

\author{
Remigijus Vasiliauskas $^{a^{*}}$, Maya Marinova ${ }^{\mathrm{b}}$, Mikael Syväjärvi ${ }^{\mathrm{a}}$, Rickard Liljedahl ${ }^{\mathrm{a}}$, Georgios \\ Zoulis $^{\mathrm{c}}$, Jean Lorenzzi ${ }^{\mathrm{d}}$, Gabriel Ferro ${ }^{\mathrm{d}}$, Sandrine Juillaguet ${ }^{\mathrm{c}}$, Jean Camassel $^{\mathrm{c}}$, Efstathios K. \\ Polychroniadis $^{\mathrm{b}}$ and Rositza Yakimova ${ }^{\mathrm{a}}$
}

\footnotetext{
${ }^{a}$ Department of Physics, Chemistry and Biology, Linköping University, SE-581 83, Linköping, Sweden.

${ }^{\mathrm{b}}$ Department of Physics, Aristotle University of Thessaloniki, GR54124, Thessaloniki, Greece.

${ }^{c}$ Groupe d'Etude des Semiconducteurs, CNRS and Université Montpellier 2, cc074-GES, 34095 Montpellier cedex 5, France.

${ }^{\mathrm{d}}$ Laboratoire des Multimateriaux et Interfaces, UMR-CNRS 5615, UCB-Lyon1, 43 Bd du 11 nov. 1918, 69622, Villeurbanne, France.
}

\begin{abstract}
In order to analyze the epitaxial growth of cubic silicon carbide by sublimation epitaxy on different substrates, four different $6 \mathrm{H}-\mathrm{SiC}$ substrates preparations were used: (i) as-received, (ii) repolished, (iii) annealed and covered by silicon layer, (iv) with (111) 3C-SiC buffer layer. Almost 100\% coverage and low twin density was achieved when growing on the buffer layer. The XRD and TEM characterizations show better material quality when layer is grown directly on $6 \mathrm{H}-\mathrm{SiC}$ substrates. Background doping evaluated by LTPL is in the range of $10^{16} \mathrm{~cm}^{-3}$ for $\mathrm{N}$ and $10^{15} \mathrm{~cm}^{-3}$ for $\mathrm{Al}$ in all grown layers.
\end{abstract}

Keywords: A1. Nucleation, A1. Characterization, A1. Substrates, A3. Vapor phase epitaxy, B1. Cubic Silicon Carbide. 


\section{Introduction}

Silicon carbide ( $\mathrm{SiC}$ ) has long been considered as a prospective semiconductor for high-temperature, high-power and high-frequency, radiation-resistant device applications. The most common SiC polytypes (one-dimensional polymorphic modifications) are the two hexagonal ones, $4 \mathrm{H}-\mathrm{SiC}$ and $6 \mathrm{H}-\mathrm{SiC}$, as well as the $3 \mathrm{C}-\mathrm{SiC}$. The last one exhibits isotropic properties due to its cubic structure. Additionally, the 3C$\mathrm{SiC}$ is regarded advantageous over the hexagonal polytypes because it shows the highest electron mobility and lower density of the near-interface-traps in the $\mathrm{SiO}_{2} / 3 \mathrm{C}$-SiC system, due to the smaller band gap. The crucial problem hindering the development of the 3C-SiC technology is the poor availability of 3C-SiC substrates. In order to overcome problems related to lattice mismatch, as in the case of 3C-SiC growth on silicon substrates, the growth may be performed on substrates of a hexagonal polytype (4H- or $6 \mathrm{H}-\mathrm{SiC}) . \mathrm{In}$ this case, the $3 \mathrm{C}-\mathrm{SiC}$ nucleates spontaneously on the (0001) surfaces if the temperature is below $2000^{\circ} \mathrm{C}[1]$.

Stabilization of 3C-SiC nucleation is still a challenge. A number of parameters (growth temperature, supersaturation, $\mathrm{Si} / \mathrm{C}$ ratio, substrate surface, etc.) influence the polytype nucleation and growth. The substrate is one of the most influencing parameters in the growth. When growing on silicon substrates, there is $20 \%$ lattice and $8 \%$ thermal expansion coefficient mismatch. Because of this, the $3 \mathrm{C}$ SiC grown on silicon has a lot of defects (high density of stacking faults, anti-phase boundaries, microtwins) [2]. When 3C-SiC is grown on other $\mathrm{SiC}$ polytypes like $6 \mathrm{H}$ and $4 \mathrm{H}$, the problems with thermal and lattice mismatch are substantially reduced. However, other problems such as $3 \mathrm{C}$-SiC twinning and the unintentional reproduction of the substrate polytype, which creates inclusions of the substrate polytype in the 3C-SiC, appear. In order to further understand the cubic SiC nucleation and polytype stability, we have investigated growth on $6 \mathrm{H}-\mathrm{SiC}$ substrates with and without a $3 \mathrm{C}-\mathrm{SiC}$ buffer layer. The buffer layer was grown on nominally on-axis (0001) 6H-SiC substrates by the Vapor-Liquid-Solid (VLS) method. A thick 3C-SiC layer was subsequently grown on the buffer layer using sublimation epitaxy (SE) method. The results are compared with the cubic SiC grown directly on differently prepared nominally on-axis $6 \mathrm{H}-\mathrm{SiC}$ substrates. 
The paper then discusses how different substrates influence the nucleation and growth morphology as well as defect formation and their reduction in 3C-SiC layers.

\section{Experimental}

The samples were grown in a vertical quartz tube reactor (Fig. 1). The cylindrical graphite growth cell consists of a bottom piece and a lid, mounted inside thermally insulating graphite foam and heated by an inductive coil using a RF generator, operating at $40 \mathrm{kHz}$. The growth temperature was measured on the top of the lid using two-color pyrometer. Growth was performed in vacuum conditions (base pressure $\sim 10^{-5}$ mbar). The source and the substrate were separated with a graphite spacer. Therefore, there was no need to glue the substrate to the graphite crucible lid. Thus using graphite spacer enables to have more repeatable results and prevents material degradation [3]. The distance between them was $1 \mathrm{~mm}$. A polycrystalline 3C-SiC plate was used as a source. By applying temperature gradient, with a higher temperature at the source compared with the substrate, $\mathrm{Si}$ - and $\mathrm{C}$ - containing species were sublimed from the source and transported to the substrate where $\mathrm{SiC}$ was nucleated. Also, to avoid source graphitization, tantalum foil was used. It acts as a carbon getter at elevated temperatures.

The growth was performed on four types of $6 \mathrm{H}-\mathrm{SiC}$ substrates, subjected to different treatments prior to growth. Results were compared for (i) as-received substrates, (ii) substrates re-polished by NovaSiC company to minimize surface roughness; (iii) substrates annealed in a chemical vapour deposition (CVD) reactor at $1450{ }^{\circ} \mathrm{C}$ for 10 min to reveal growth steps and subsequently covered with few micron silicon layer [4]; (iv) substrates with $1.5 \mu \mathrm{m}$ 3C-SiC buffer layer grown by Vapor-Liquid-Solid (VLS) method using Si-Ge melt [5]. Before growth, all substrates were wet ex-situ cleaned with solvents (trichlorethylene, acetone and ethanol) and acid $\left(\mathrm{H}_{2} \mathrm{O}: \mathrm{NH}_{3}: \mathrm{H}_{2} \mathrm{O}_{2}\right.$ 5:1:1) to remove organic contamination, followed by inorganic contamination removal with acid $\left(\mathrm{H}_{2} \mathrm{O}: \mathrm{HCl}: \mathrm{H}_{2} \mathrm{O}_{2}\right.$ 6:1:1) and lastly, with $\mathrm{HF}$ $\left(\mathrm{H}_{2} \mathrm{O}: \mathrm{HF} 3: 1\right)$ to remove silicon oxide layer. The growth experiments, except the ones on the VLS buffer layer, were performed on the Si-face of nominally on-axis (0001) $6 \mathrm{H}-\mathrm{SiC}$ substrates $( \pm 0.5 \mathrm{deg}$ as specified by supplier). Identical growth conditions were used: growth temperature $1775^{\circ} \mathrm{C}$, growth duration $30 \mathrm{~min}$, and a temperature ramp-up of $5 \mathrm{~K} / \mathrm{min}$ [6]. Also, to reveal nucleation mechanism of 3C$\mathrm{SiC}$ on the VLS buffer layer, one very short growth run was performed. In this case only a temperature 


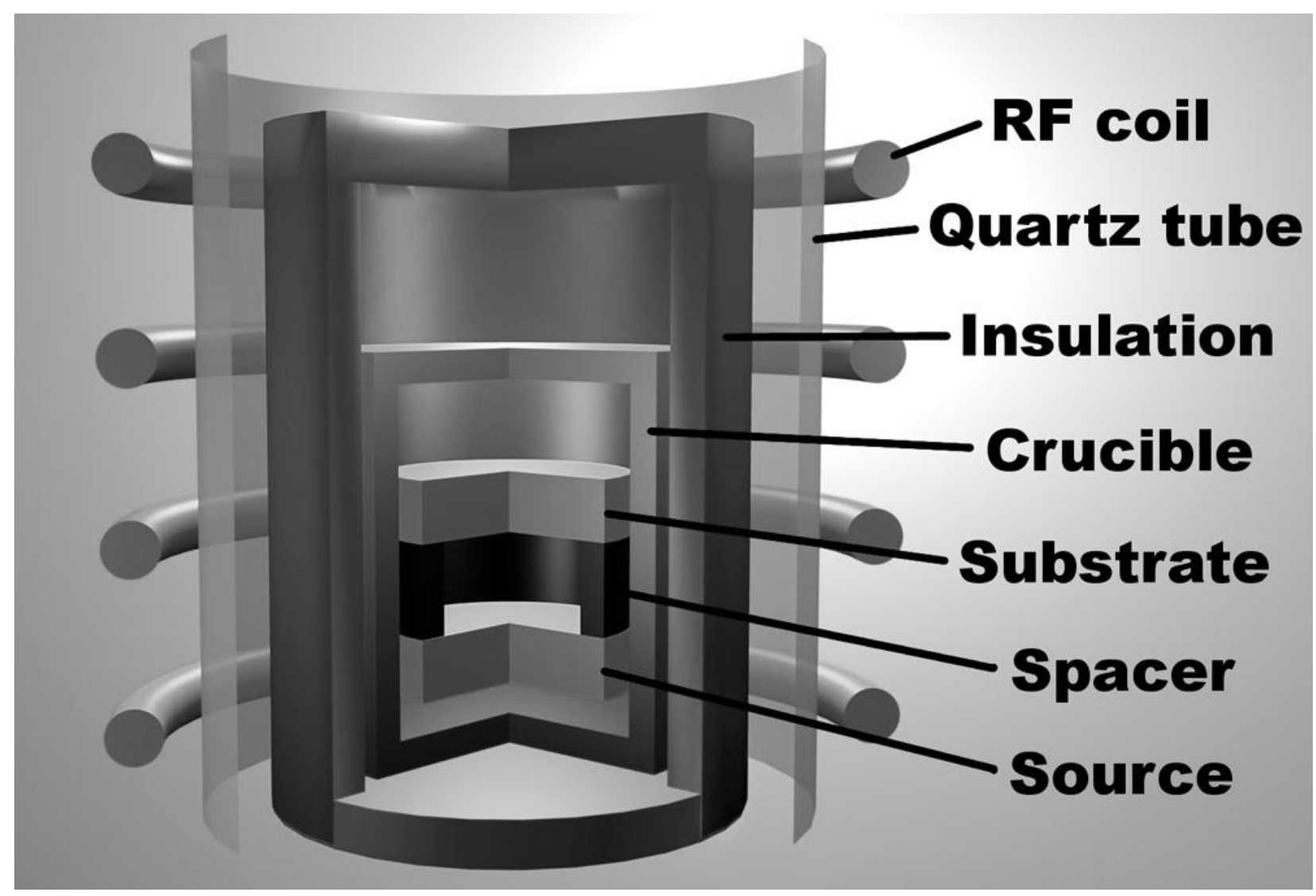

Fig. 1. Growth arrangement for sublimation epitaxy.

ramp-up until $1755^{\circ} \mathrm{C}$ was used, and then growth was terminated by turning off the heating so that only initial nucleation occured. The 3C- or $6 \mathrm{H}-\mathrm{SiC}$ polytypes were identified by their color (yellow for $3 \mathrm{C}$ and green/blue for $6 \mathrm{H}$ in transmitted light) using an optical microscope with Nomarski interference contrast (OM), and by Raman spectroscopy. Surface morphology of grown layers was studied with OM and Atomic Force Microscopy (AFM). The low temperature photoluminescence (LTPL) spectroscopy was applied in order to estimate the type and concentration of residual impurities. The LTPL spectra were collected at $5 \mathrm{~K}$, using $20 \mathrm{~mW}$ of the $244 \mathrm{~nm}$ wavelength of a frequency doubled Ar+-ion laser as excitation source. The detection limit (DL) of the setup depended on the impurity. It was $\sim 10^{14} \mathrm{~cm}^{-3}$ for Al but only $\sim 10^{16}$ to $10^{17} \mathrm{~cm}^{-3}$ for $\mathrm{N}$ [7]. The structural quality of the grown material at large scale was studied by using the omega angle (rocking scans) X-Ray Diffraction (XRD) measurements on the Si-face of the samples by using the (111) Bragg reflection. The measurements were done using Philips X'Pert high-resolution $\mathrm{x}$-ray diffraction (HRXRD) diffractometer operating in triple-axis mode with $\mathrm{Cu} \mathrm{K} \alpha 1$ anode at $45 \mathrm{kV}$ voltage and $40 \mathrm{~mA}$ current. The HRXRD was operated with (Ge 220) four reflection 
monochromator at the tube side and three reflection monochromator at the detector side. Finally, the crystal structure of the layers on a micro-scale was investigated by Transmission Electron Microscopy (TEM). The TEM observations were performed in plane-view on JEOL 100CX conventional microscope.

\section{Results and discussion}

\subsection{Heteroepitaxial growth on polished SiC surfaces}

In the epitaxy of $\mathrm{SiC}$ it is common that the growth is performed on bare substrates which then may be used as-received from a vendor with standard polishing on the surface of interest, or they can be prepared for example by an additional fine re-polishing step to decrease the surface roughness. To analyze the influence of additional polishing or, in other words, surface roughness of the substrate on the growth of cubic SiC, we have compared growth on as-received and re-polished substrates. For this purpose, AFM images from the $20 \times 20 \mu \mathrm{m}^{2}$ area were acquired to confirm the difference in surface roughness. The obtained root mean square (rms) roughness of the as-received substrate was $2.6-2.8 \mathrm{~nm}$ and rms of the re-polished substrate was $0.3-0.6 \mathrm{~nm}$. From this substantial difference in roughness one can expect that the different surfaces affect nucleation and growth in different ways. This was earlier demonstrated in CVD growth of $\mathrm{SiC}[8,9]$. In CVD more rough surfaces usually promote the nucleation of 3C polytype, but generates a higher density of twin boundaries due to uncontrolled nucleation. Smoother surfaces favor formation of more regular and controlled two-dimensional 3C-SiC island formation, and consequently better quality 3C-SiC deposit. However, in our case there was no significant difference between the layers grown by sublimation epitaxy on as-received and re-polished substrates. The coverage of 3C-SiC was about $87 \%$ in both cases (fig. $2 \mathrm{a}, \mathrm{b}$ ) and thickness of the grown material was about 140-190 $\mu \mathrm{m}(280-380 \mu \mathrm{m} / \mathrm{h}$ growth rate). Thus, an initial smoother surface prepared by polishing did not influence the $3 \mathrm{C}-\mathrm{SiC}$ nucleation much. This was most probably due to the following two reasons. The first one, is that before actual sublimation epitaxy growth, the substrate surface can undergo changes. The sublimation of the substrate surface during the initial temperature ramp-up stage occurs and smoothens the surface. We estimate that about one or two micrometers of the surface is sublimed away at the initial stage of the growth. This initial substrate sublimation seems to be enough to reduce the difference between re-polished and as-received surface. Another reason is that there is an initial homoepitaxial $6 \mathrm{H}-$ 
$\mathrm{SiC}$ growth at the temperature ramp up, that creates perfectly on-axis regions. This makes large enough terraces for two dimensional nucleation, instead of nucleation at steps which would replicate the $6 \mathrm{H}-\mathrm{SiC}$ substrate, and is very important for the $3 \mathrm{C}-\mathrm{SiC}$ formation $[10,11]$.
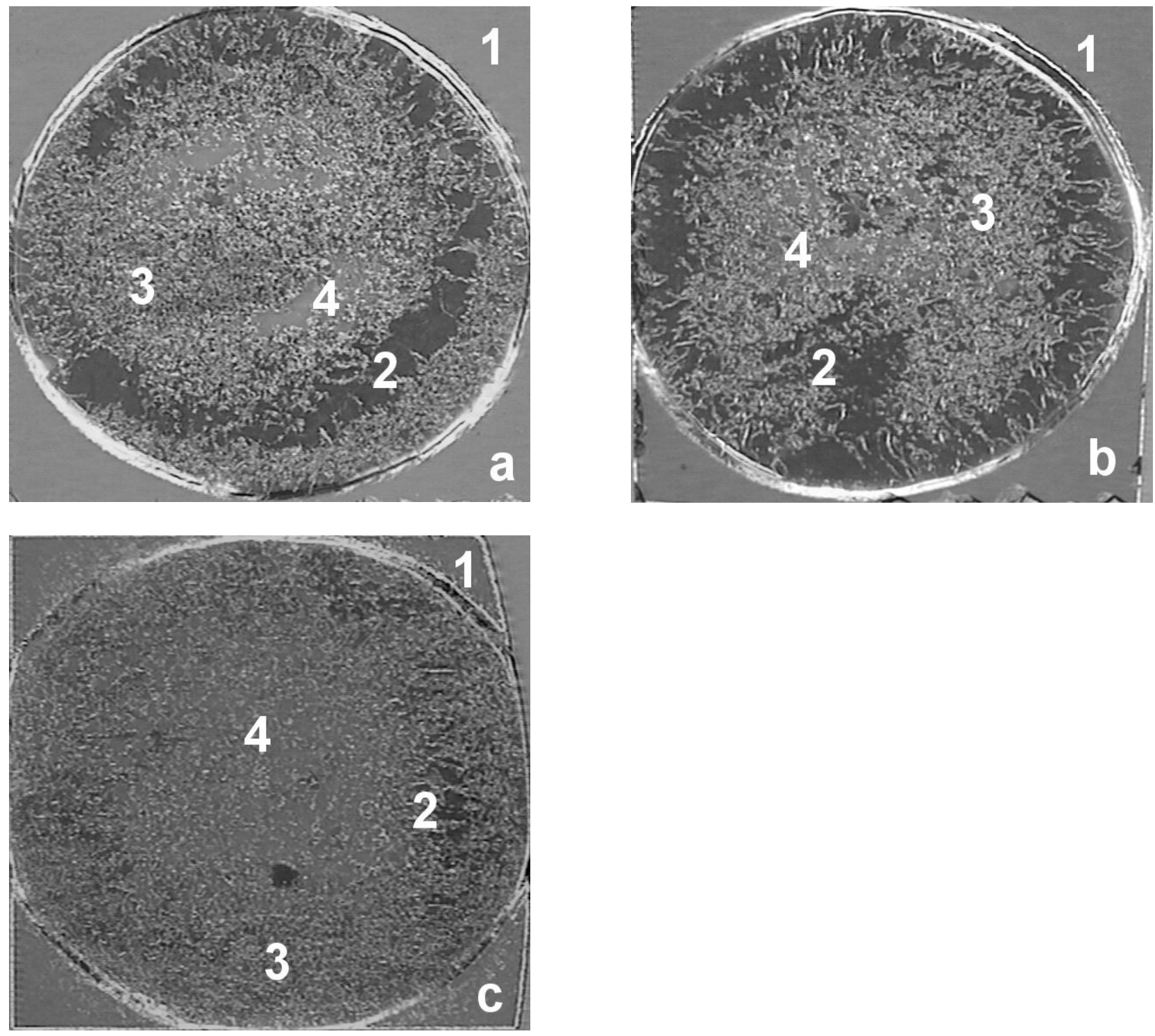

Fig 2. Different coverage of the substrate by 3C-SiC when growing on: a) as received, b) re-polished, c) annealed and covered with silicon substrates. Here $1-6 \mathrm{H}-\mathrm{SiC}$ substrate, $2-3 \mathrm{C}$-SiC domains with low density of DPBs, 3 - small 3C-SiC domains and homoepitaxial 6H-SiC, 4 - homoepitaxial 6H-SiC. Here the sample diameter in all figures is $10 \mathrm{~mm}$.

Other important parameters describing the crystalline quality of the grown $3 \mathrm{C}-\mathrm{SiC}$ are the presence and density of (i) the twinned domains and the corresponding twin boundaries, and (ii) the stacking faults (SFs). Twin domains occur frequently when an fcc material is grown in a (111) orientation on the basal plane of a hexagonal crystal, since there are two types of equally possible stacking sequences, in both of which the close-packed directions are aligned in the interface. On the $6 \mathrm{H}-\mathrm{SiC}$ 
(0001) there are two equivalent types of sites on which growth of cubic SiC can proceed. The two types of nuclei orientations can be formed on the surface with a rotation of 60 degrees relative to each other. The boundary between such nuclei is a double position boundary (DPB). The DPBs are rather high formation energy extended defects which usually relax by creating stacking faults (SF) [12]. Both types of extended defects are reported to increase strongly the leakage current at the pn-junction [13]. The characteristics of the pn junctions depend not only on the presence of these defects but also on the type of the defect. For example the SF densities above $10^{3} \mathrm{~cm}^{-1}$ severely affect the device performance and thus the density of the SF should be reduced below this value. Additionally the twin boundaries are most generally divided in incoherent and coherent boundaries. The incoherent ones are highly defective and

they are usually associated with enhanced SF density and $\alpha$-SiC polytypic inclusions. The propagation of such boundaries to the surface of the layer results in ohmic behavior of Schottky contacts [14]. The influence of the coherent ones is not well understood and theoretical predictions show that they should be less detrimental as far as the electrical performance of the material is concerned [15]. Thus the reduction of all these extended defects is needed to have good quality crystals.

On the as-received and re-polished substrates mostly small $(50-100 \mu \mathrm{m})$, twinned domains dominate. Nevertheless, in both cases there are big, twin free domains $\left(\sim 0.5 \times 2 \mathrm{~mm}^{2}\right)$ (marked by number 2 in fig 2), which in case of re-polished substrate are slightly larger. These domains are very promising, but further optimization of growth parameters is needed to increase the size of the twin free domain.

\subsection{Heteroepitaxial growth on pre-treated surfaces}

Another way to reveal further information about the initial surface effect is to pre-treat the substrate surface. An ex-situ annealing of the $6 \mathrm{H}-\mathrm{SiC}$ substrate under $\mathrm{H}_{2}$ atmosphere for $10 \mathrm{~min}$ at $1450{ }^{\circ} \mathrm{C}$ was done. After annealing a smooth surface with parallel steps with width of $\sim 380 \mathrm{~nm}$ and height of $\sim 0.7 \mathrm{~nm}$ is achieved (Fig. 3a). The subsequent coverage by thin silicon layer is done to protect surface from oxidation and dust during transportation to the growth reactor. This is a standard substrate preparation procedure for cubic SiC growth by VLS method [4]. 

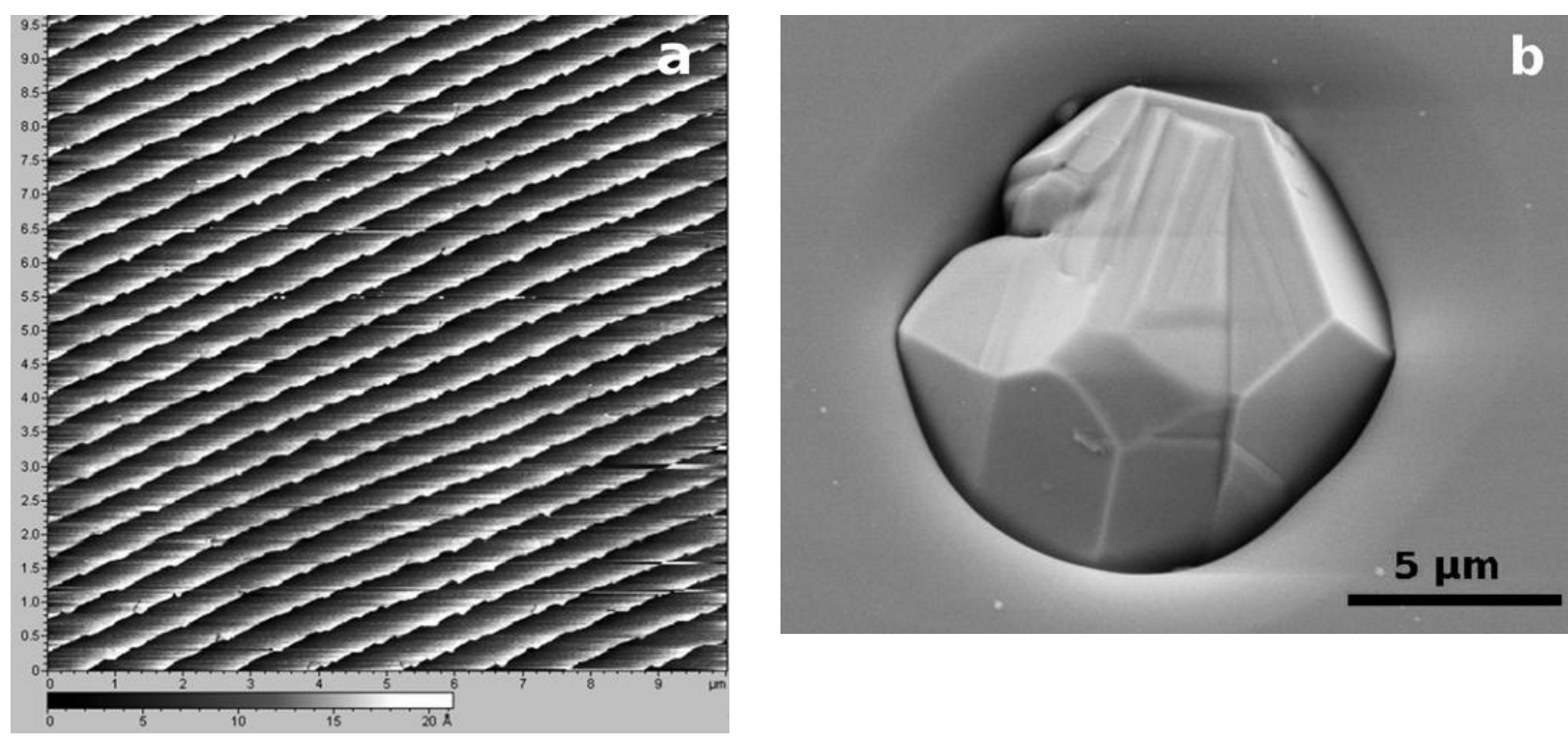

Fig 3. a) AFM image of 6H-SiC substrate surface after annealing [4]. Smooth surface with parallel steps can be seen; b) SEM image of SiC hillock formed due to enhanced growth on silicon droplet.

The growth on these pre-treated surfaces we compare with the growth of 3C-SiC using surfaces of untreated substrates which were discussed in the previous section. However, growth on annealed and silicon covered substrates showed less nucleation of 3C-SiC ( $45 \%$ only) and the thickness was around $100 \mu \mathrm{m}(\sim 200 \mu \mathrm{m} / \mathrm{h}$ growth rate) (table 1) and most of it was homoepitaxial $6 \mathrm{H}-\mathrm{SiC}$ growth, which appear before 3C-SiC starts to nucleate. One can argue that this is resulting from the excess of silicon on the substrate surface, which should disturb growth similarly to CVD where silicon droplets are formed [16]. On the surface of the grown material we noticed SiC hillocks (fig. 3b), which are higher than the layer. They could have formed because of enhanced growth of $\mathrm{SiC}$ on silicon droplets. The highest density of the hillocks is in the places where coverage by $3 \mathrm{C}-\mathrm{SiC}$ is highest. Thus even if there are silicon droplets, the increase of $\mathrm{Si} / \mathrm{C}$ ratio generally increases the probability of $3 \mathrm{C}-\mathrm{SiC}$ formation, however we have an opposite result. On the other hand, the annealing is performed to reveal steps, which favor 3CSiC growth during the VLS process [4]. In the VLS process the 3C-SiC starts to nucleate at the terraces of these steps. However, in the vapor phase growth the steps enhance growth at the ledges, and results in reproduction of the $6 \mathrm{H}-\mathrm{SiC}$ substrate polytype, as supported by the lower percentage of 3C-SiC when using annealed substrates. Thus the growth mechanism in this case is mainly governed by step-controlled growth, and $3 \mathrm{C}-\mathrm{SiC}$ is not likely to form heteroepitaxially on the $6 \mathrm{H}-\mathrm{SiC}$ substrate. The results from these 
experiments suggest that optimized conditions for growth of cubic SiC should be derived by strongly considering the growth method.

\subsection{Homoepitaxial growth on VLS buffer layer}

Low twin density and twin-free cubic SiC surfaces have been demonstrated using VLS growth mechanism on $6 \mathrm{H}-\mathrm{SiC}(0001)$ substrates [17]. This approach involves feeding a Si-Ge melt by propane flux at temperature ranging from 1250 to $1550^{\circ} \mathrm{C}$. Propane acts as a carbon source to the melt. Carbon which is dissolved in the melt will migrate to the substrate driven by the carbon activity gradient between the top and the bottom of the liquid, where SiC substrate is situated and 3C-SiC is then formed. However this method leads to moderate growth rates $(2-5 \mu \mathrm{m} / \mathrm{h})$ and thereby mainly produces thin layers. High growth rate sublimation epitaxy was cand be applied to fabricate bulk-like dimension VLS grown layers with a low twin density.

To identify the nucleation mechanism on VLS grown 3C-SiC buffer layer we have done very short growth run by just ramping up the temperature to $1755^{\circ} \mathrm{C}$ and terminating the growth at its initial nucleation stage, while all other growth parameters were the same as in the growth of thick layers. Earlier [10] similar experiments were done on $6 \mathrm{H}-\mathrm{SiC}$ substrates to study two-dimensional nucleation. No 2D islands of 3C-SiC appear in the growth on VLS buffer layer and we observed that the surface became smoother. This indicates that here the growth is not governed by 2D nucleation, but step controlled growth of 3C-SiC.

To compare heteroepitaxial growth of $3 \mathrm{C}-\mathrm{SiC}$ with homoepitaxial a growth run for $30 \mathrm{~min}$ at $1775^{\circ} \mathrm{C}$ on VLS buffer layer was done. As a result of the predominant homoepitaxial growth, the coverage by $3 \mathrm{C}$ $\mathrm{SiC}$ was as high as $99 \%$ and the thickness of the grown material was around $170 \mu \mathrm{m}$ (corresponding to $340 \mu \mathrm{m} / \mathrm{h}$ growth rate) (table 1). Also there were no small domains, but just few large almost twin free areas $\left(2 \mathrm{x} 4 \mathrm{~mm}^{2}\right)$, giving much less twin boundaries which were reaching the surface compared with heteroepitaxial growth. The twin boundaries most probably propagate from the VLS layer.

The surface morphology of $3 \mathrm{C}-\mathrm{SiC}$ buffer layer, grown by VLS, is shown in figure 4a. It exhibits stepbunched triangular steps which are characteristic of VLS method. The facets of the triangular steps meet 
at 60 degrees to each other. The height of the steps is in the range of 10-30 nm. Comparable triangular features also appear on the surface of the sublimation grown layers on the VLS buffer layer (fig. 4b) and 6H-SiC substrates (fig. 4c). The difference in features which are on the layers grown by sublimation epitaxy compared to steps on the buffer layer is their height $(\sim 50-200 \mathrm{~nm})$, they are larger in size and their density is much lower. On the other hand, there are differences in triangular features on the $3 \mathrm{C}-\mathrm{SiC}$ grown on VLS buffer layer (fig. 4b) and on 6H-SiC substrates (fig. 4c). They are different in density, size and distribution. In the layer grown on $6 \mathrm{H}-\mathrm{SiC}$ substrates the density (calculated from ten different spots on the sample) is $\sim 5 \times 10^{4} \mathrm{~cm}^{-2}$ and distribution is quite uniform. They are larger, but have smaller height and a larger distance between them. Also it is worth noticing here, that triangular features were identical on the 3C-SiC layers grown on re-polished and as-received substrates. However, in layers grown on VLS buffer layer, the density of triangular features is almost one order of magnitude higher, $\sim 2 \times 10^{5} \mathrm{~cm}^{-2}$, and has a non uniform distribution. The facets of the triangular features meet at 60 degrees and thus one can suggest that they form tetrahedral defects along the closed packed $\{\overline{1} 11\}$ planes. These defects could be formed by single or repeated SFs or $6 \mathrm{H}-\mathrm{SiC}$ inclusions formed along these ${ }^{\{\overline{1} 11\}}$ planes.

It is known that $3 \mathrm{C}-\mathrm{SiC}$ nucleates in two-dimensional nucleation on on-axis $6 \mathrm{H}-\mathrm{SiC}$ substrates [10] and we saw that on the buffer layer the growth is in the step controlled way. From this we would expect larger differences on the surface of grown material. This suggests that growth of $3 \mathrm{C}-\mathrm{SiC}$ on $6 \mathrm{H}-\mathrm{SiC}$ substrates after 2D-nucleation, proceeds by island expansion and growth in a step controlled way, while on buffer layer growth proceeds only in a step controlled way.

\subsection{XRD measurements}

In order to further compare 3C-SiC layers grown heteroepitaxially and homoepitaxially, XRD $\omega$-rocking curve measurements have been done on 3C-SiC layers grown on VLS buffer layer and directly on asreceived $6 \mathrm{H}-\mathrm{SiC}$ substrates. The measurements were performed by scanning the whole sample with a footprint size of $2 \times 2 \mathrm{~mm}^{2}$. The full width at half maximum (FWHM) for material grown on the VLS buffer layer showed a large spread (116-700 arcsec) over the sample. The best values were measured at 

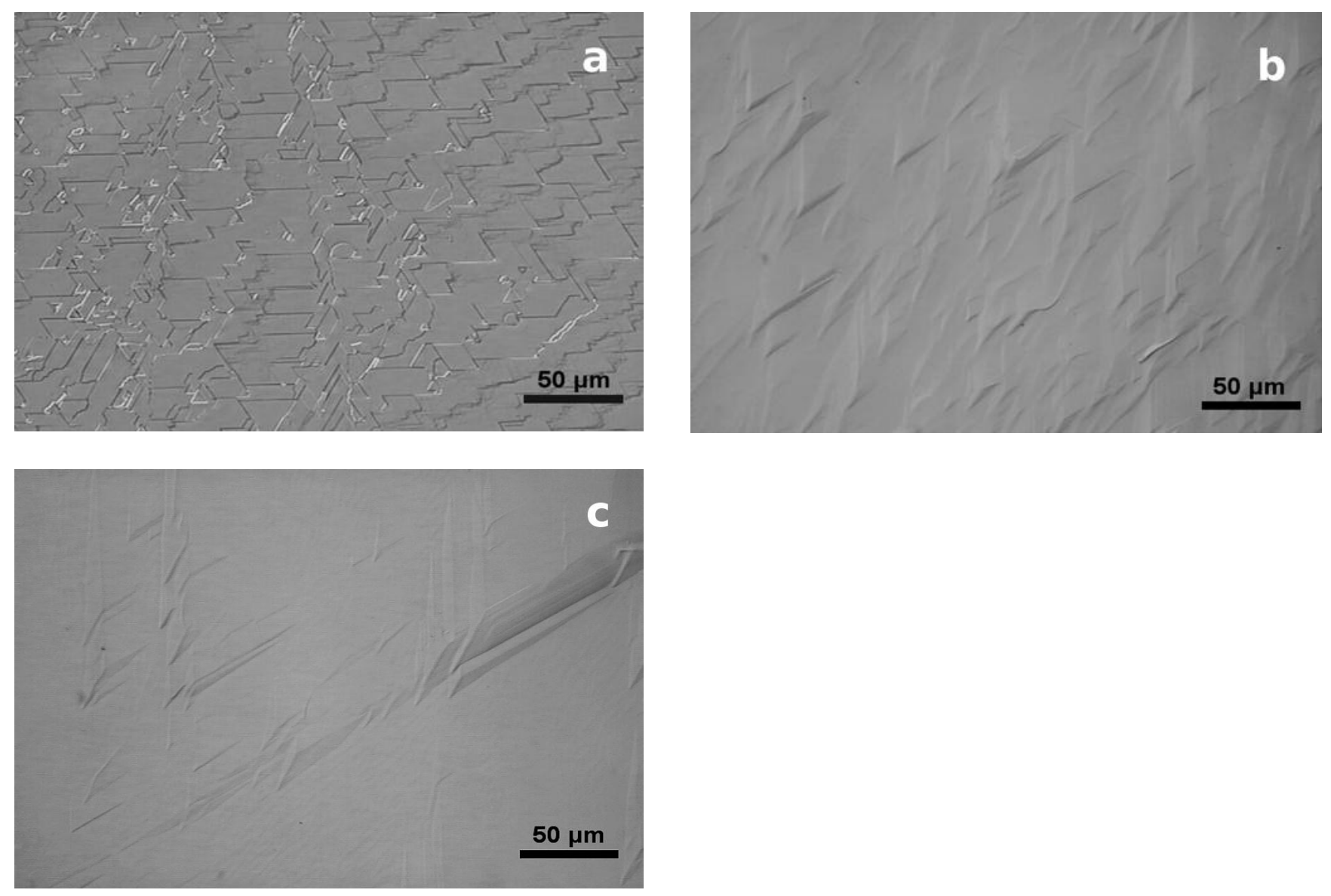

Fig 4. a) Triangular steps on a VLS buffer layer; Triangular features on the surface of 3C-SiC when growing on b) VLS buffer layer, c) $6 \mathrm{H}-\mathrm{SiC}$ substrates.

the smoothest place with the smallest number of triangular features on the surface. This strongly proposes that triangular features must be defect related. On the other hand, the $3 \mathrm{C}-\mathrm{SiC}$ layer grown directly on $6 \mathrm{H}-$ SiC shows FWHM of 88 arcsec (fig. 5a) (table 2). However, it was not possible to measure the spread of FWHM over the whole sample because of $6 \mathrm{H}-\mathrm{SiC}$ inclusions, which are influencing the measurements.

So even if there is more DPBs and smaller domains on the surface of $3 \mathrm{C}-\mathrm{SiC}$ grown directly on $6 \mathrm{H}-\mathrm{SiC}$, the material quality distanced from the DPBs is better than 3C-SiC grown on a buffer layer. This is attributed to a higher defect density (stacking faults) in the buffer layer. It is evidenced by TEM measurements that even if the defect density is decreased in the epilayer compared to the buffer layer, there are still more of them left than in the layer grown directly on $6 \mathrm{H}-\mathrm{SiC}$. 

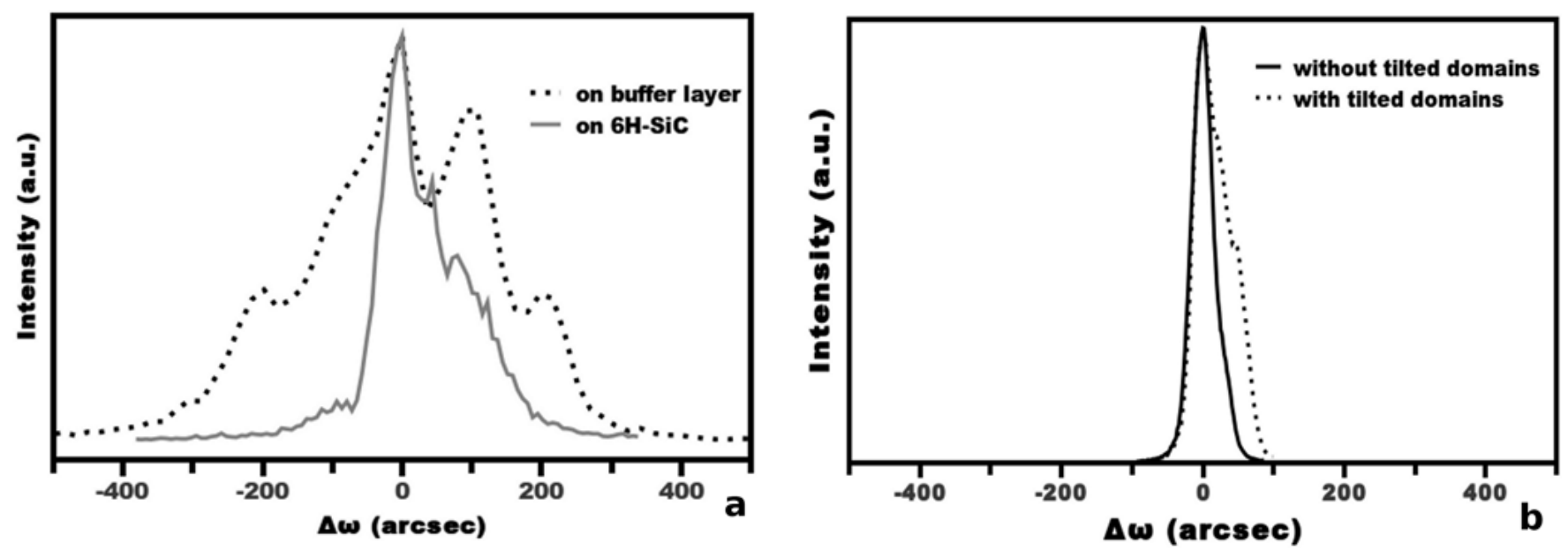

Fig 5. XRD $\omega$-rocking curve of a) the 3C-SiC grown on buffer layer (FWHM is $\sim 200$ arcsec) and on $6 \mathrm{H}-$ $\mathrm{SiC}$ substrate (FWHM is 88 arcsec), b) $6 \mathrm{H}-\mathrm{SiC}$ substrate without and with tilted domains (FWHM 37 and 63 arcsec, respectively).

Also in both $\omega$-rocking curves (fig. 5a) one can notice several peaks indicating that the crystal consists of several domains, slightly (50-400 arcsec) tilted to each other [18]. Similar observations have been done on $6 \mathrm{H}$ and $4 \mathrm{H}-\mathrm{SiC}$ epilayers [19-21 ]. The misoriented domains on 3C-SiC can appear because of two-dimensional nucleation. There are a lot of nuclei in the beginning of the growth. During the growth they expand laterally and at some time they meet each other. Several consequences can occur, (i) if the islands are rotated to each other (twinned) they will create an extended defect - twin boundary, (ii) if the islands are not twinned they can meet each other in perfect stacking or (iii) they can meet with a small angle between them. The small angle between the islands can appear because of similar misoriented domains on the substrate or if the substrate is rough. We have measured $\omega$-rocking curves on the $6 \mathrm{H}-\mathrm{SiC}$ substrate to examine if there are tilted domains on the substrate (fig $5 \mathrm{~b}$ ). The measurements were performed similarly like on $3 \mathrm{C}-\mathrm{SiC}$ by scanning the sample with a footprint size of $2 \times 2 \mathrm{~mm}^{2}$. From the $\omega$ rocking curves we can see that there are areas with and without tilted domains. The measured curve in the area with tilted domains looks very similar to the one measured on 3C-SiC layer grown directly on $6 \mathrm{H}-$ $\mathrm{SiC}$ substrates. This indicates that the substrate is giving rise to the tilted domains and during the growth of the layer the tilt angle has increased. However, the epilayer grown on the buffer layer has much more tilted domains, indicating that there are other factors than just bare substrate giving rise to these domains. One of these factors could be the roughness of the buffer layer (RMS is 10-15 nm, measured by AFM on 
$20 \times 20 \mu \mathrm{m}^{2}$ area), which is much higher compared with the $6 \mathrm{H}-\mathrm{SiC}$ substrate (RMS is $2-3 \mathrm{~nm}$ on $20 \times 20$ $\mu \mathrm{m}^{2}$ area) and can give rise to more misoriented domains.

\subsection{TEM investigation}

The microstructure of the 3C-SiC layers was further investigated by TEM in plane-view (PVTEM). The major defects within all studied layers were twins and related twin boundaries (TB). The TBs and their atomic structure strongly affect the electronic properties of the material through generation of gap states or interactions with impurities [22]. A typical bright field (BF) PVTEM micrograph in the $\{110\}$ zone section from the layer grown on as-received $6 \mathrm{H}-\mathrm{SiC}$ substrates is shown in the figure 6a. Here the multiple repetitions of small twinned lamellae can be seen. The small complexes composed of four twins marked by T1-T4, twinned along the different $\{\overline{1} 11\}$ planes, indicated by white lines in the figure $6 \mathrm{~b}$. Moreover, the TEM micrograph and the corresponding selected area diffraction pattern (SADP) in Fig. 7 (a), (b) and (c), reveal that the multiple introduction of SFs and/or lamellae of twinned grains can form a faceted twin boundary. The repeated introduction of SFs can in addition lead to formation of $6 \mathrm{H}-\mathrm{SiC}$ inclusions following any of the ${ }^{\{\overline{1} 11\}}$ planes as shown in Fig. 7 (d).

The SF density was estimated only in the areas slightly away from the twin boundaries while the areas close to the boundaries are too defective and do not represent layer quality. First it should be mentioned, that there was no difference in stacking faults density when cubic SiC layers were grown on as-received or re-polished substrates. Thus in the layers grown on $6 \mathrm{H}-\mathrm{SiC}$ substrates the estimated SF density in different areas varies from $2 \times 10^{4}$ to $5 \times 10^{3} \mathrm{~cm}^{-1}$. In comparison, in the layers grown on the VLS buffer layer the SF density was measured to be on average $\sim 1 \times 10^{4} \mathrm{~cm}^{-1}$ (table 2 ) which is slightly less than the SF density of a VLS layers grown in $\mathrm{Si}_{50} \mathrm{Ge}_{50}$ melts $\left(\sim 3 \times 10^{4} \mathrm{~cm}^{-1}\right.$ [23]). Thus there is no significant difference between SF densities in 3C-SiC layers grown on 6H-SiC substrates and on VLS buffer layer and also there is only slight improvement in the material quality grown by sublimation epitaxy compared to the buffer layer. Also it should be noticed that for both layers grown by sublimation epitaxy on $6 \mathrm{H}-\mathrm{SiC}$ substrates and on VLS buffer layer, the SF density will decrease below the TEM 
detection limit $\left(1 \times 10^{3} \mathrm{~cm}^{-1}\right)$ distanced away from the twinned domain boundaries. The SF density is one order of magnitude lower than in buffer layer and shows that low SF density can be achieved if twin boundaries are eliminated.
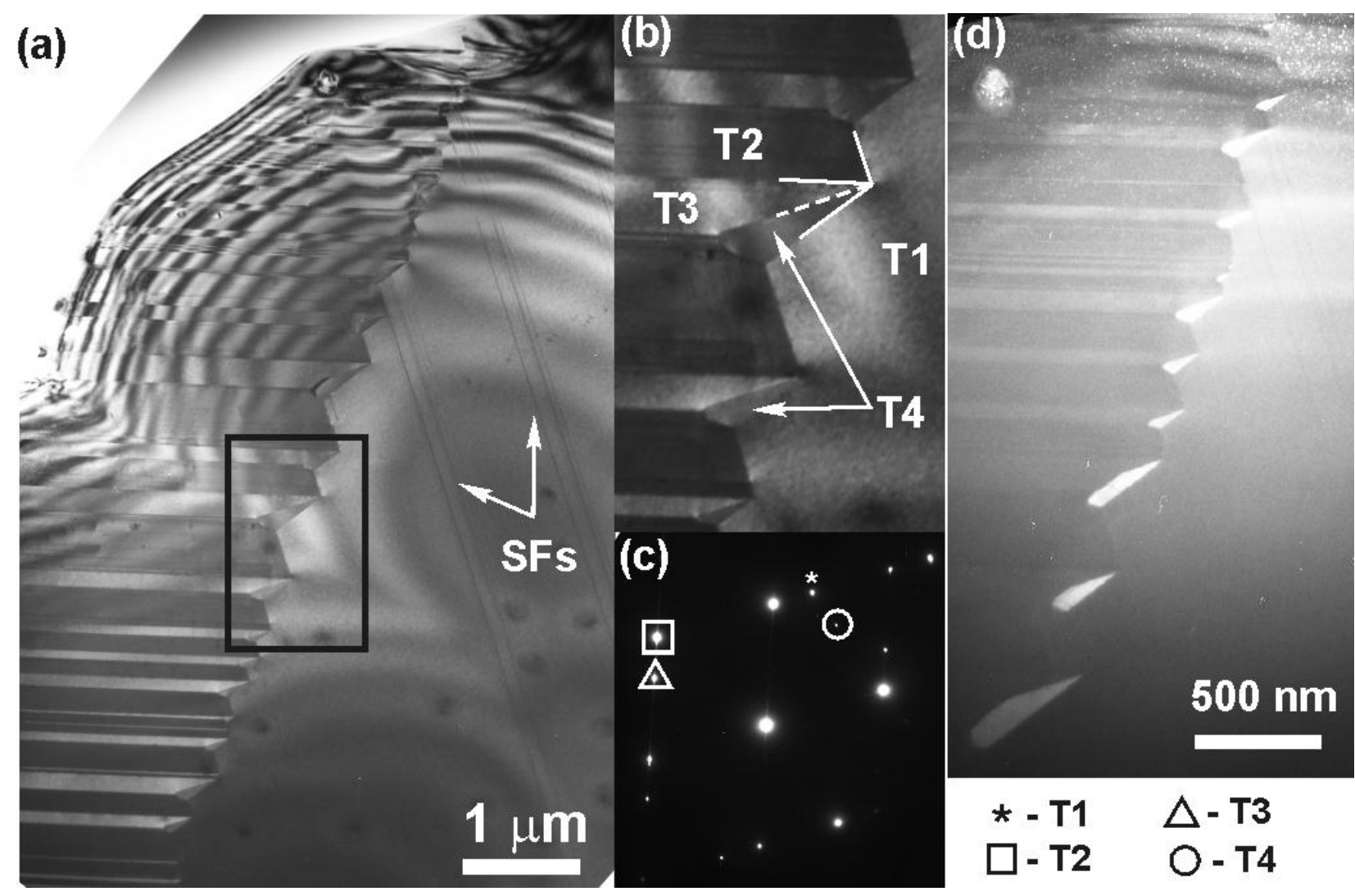

Fig. 6. PVTEM photos from the layer grown on as-received 6H-SiC substrates (a) BF micrograph; (b) A photo at higher magnification from the area marked with rectangle in (a); (c) SADP where the reflections due to twin $\mathrm{T} 1$ are indicated with *, the ones due to T2 with open square, the ones due to twin T3 with one triangle and the ones due to $\mathrm{T} 4$ with open circle.

\subsection{Photoluminescence study}

The difference in growth mode can have an influence in the incorporation of impurities [24]. The heteroepitaxial and homoepitaxial layers were studied using photoluminescence measurements. Low temperature PL is a typical characterization technique for $\mathrm{SiC}$, and the impurities are detected by characteristic peaks in the spectra.

In Fig. 8 LTPL spectra from both samples are shown. These spectra are taken from the large areas of 3C-SiC. In Fig. 8 a) the $\mathrm{N}$ bound exciton and the phonon replicas of 3C-SiC are evident. There is a weak peak of the $\mathrm{Al}$ bound exciton at $\sim 2.365 \mathrm{eV}$ [25] for both samples while there is no trace of the Donor Acceptor Pair (DAP) complex, this absence indicates that there is no compensation in these areas of the 

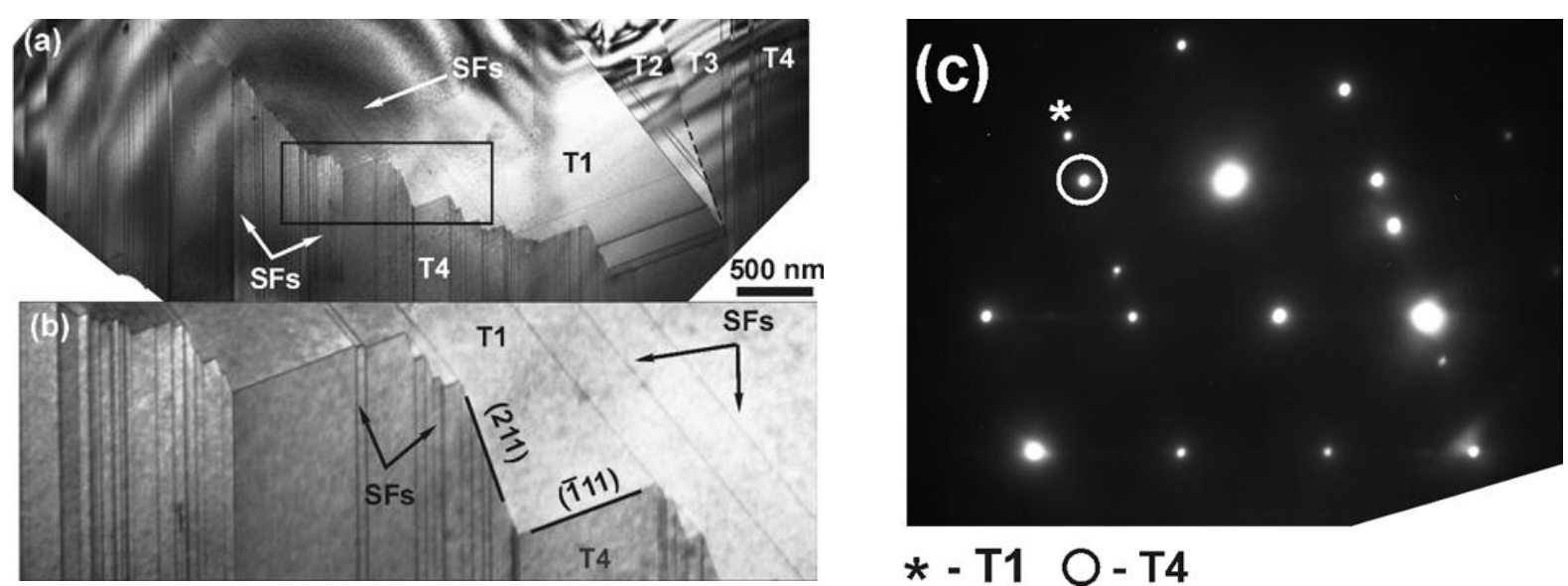

* - T1 O-T4

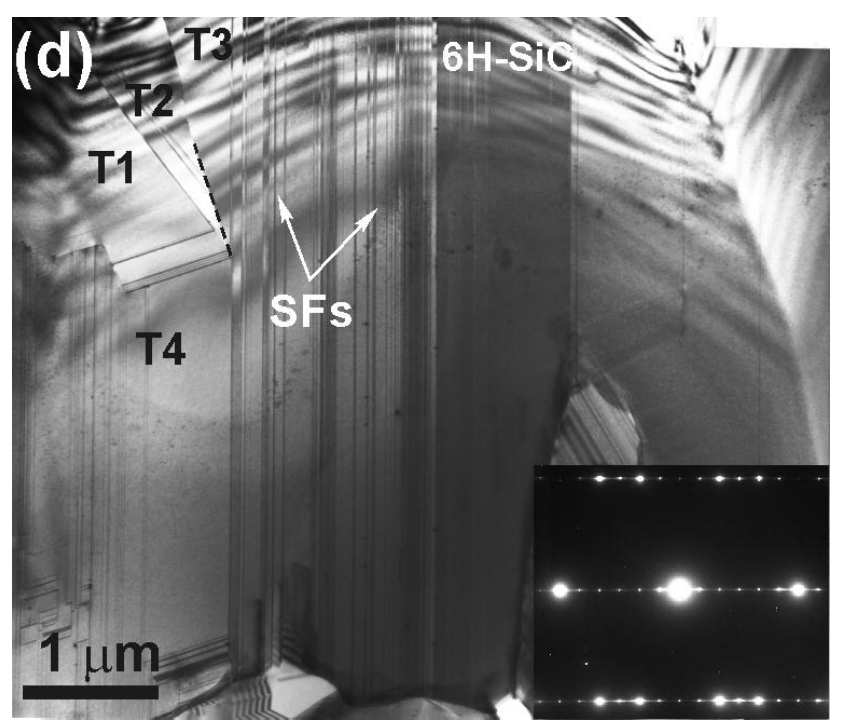

Fig. 7. PVTEM photos from the layer grown on as-received 6H-SiC substrates (a) BF micrograph; (b) an image at higher magnification from the area marked with rectangle in (a); (c) the corresponding SADP; (d) the formation of a $6 \mathrm{H}-\mathrm{SiC}$ inclusion as a result of multiple introduction of SFs in an area close to the one shown in a panel (a).

samples. The inserts in Fig. 8a show the spectral area of the 3C-SiC in more detail where the Near Band Edge (NBE) excitons are evident. In other areas of the samples a very weak signal of the DAP complex appears, as it can be seen in Fig.8b, indicating a very weak compensation. The fact that DAP transitions appear in other point shows that there is a fluctuation of the impurity concentration in the layers especially for Al. Such fluctuations could be related to the difference in dopant incorporation in high quality and defective material.

Both sample types exhibited Multi Bound Exciton Complexes (MBEC) that are linked with the possibility of the $\mathrm{N}$ neutral bound exciton to trap more than one exciton [26]. The two conditions for achieving this are that there are more excitons created than the impurities can trap and that the density of defects is low enough so that these weak transitions can be observed. 

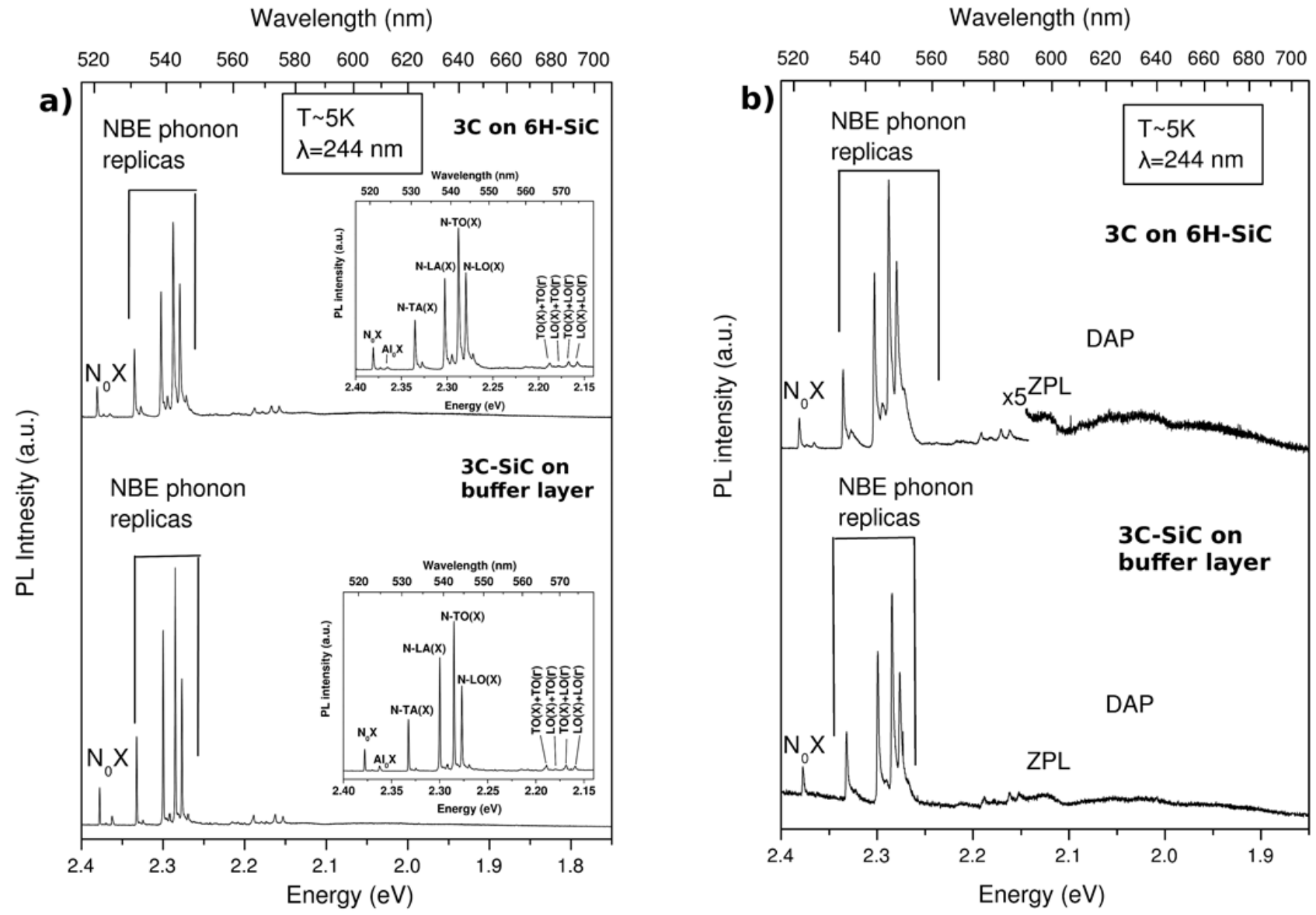

Fig. 8. LTPL spectra of a) 3C-SiC layer grown on $6 \mathrm{H}-\mathrm{SiC}$ substrate and VLS buffer layer. In the inserts details of Near Bound Edge excitons and phonon replicas can be seen. b) Two points of the samples where the DAP signal appear. For $3 \mathrm{C}-\mathrm{SiC}$ layer grown on $6 \mathrm{H}-\mathrm{SiC}$ the DAP area was magnified 5 times.

The peaks from more complex phonon transitions also appear in the energy region 2.15 and $2.20 \mathrm{eV}$ that are a combination of two Transverse and/or Longitude Optical phonons on the $\Gamma$ and $\mathrm{X}$ high symmetry points. These transitions have low probability of appearing, hence the very low PL intensity, and appear when the density of non-radiative defects is quite low. These results indicate that overall quality of 3C-SiC layers grown on both substrates is high.

The FWHM of the nitrogen bound exciton $\left(\mathrm{N}_{0} \mathrm{X}\right)$ lines for sample grown on $6 \mathrm{H}-\mathrm{SiC}$ and on the buffer layer are $\sim 1.7 \mathrm{meV}$ and $\sim 1.0 \mathrm{meV}$, respectively. The FWHM of the reference samples $\mathrm{N}_{0} \mathrm{X}$ line is $\sim 1.3$ $\mathrm{meV}$. This is an indication that the crystal quality of these samples is in par with the reference $3 \mathrm{C}-\mathrm{SiC}$ bulk like sample described in [27]. In general the phonon replica lines are well defined for both samples and the $3 \mathrm{C}-\mathrm{SiC}$ layer grown on a buffer layer at the best place displays very low background which points in better crystalline quality. 
From the LTPL it was also possible to extract the level of n-type doping using the FHWM of the TAphonon replica of the ZPL (zero-phonon line) of the nitrogen bound exciton [28], combined with the calibration curve of Ref: [7]. For the Al doping, a combination of Al bound exciton line intensities with the intensity of the $\mathrm{N}-\mathrm{Al}$ donor-acceptor pair intensities were used. From these evaluations, the mean value of the N-type doping is $[\mathrm{N}] \sim 3.3( \pm 1.4) \times 10^{16} \mathrm{~cm}^{-3}$ and of the Al-doping is $[\mathrm{Al}] \sim 3.7( \pm 1.7) \times 10^{15} \mathrm{~cm}^{-3}$ for 3C-SiC layer grown on VLS buffer layer. From the LTPL spectra of 3C-SiC grown on 6H-SiC substrate we can evidence a similar level of non-intentional $\mathrm{N}$ and $\mathrm{Al}$ doping as in one grown on buffer layer. From these evaluations, the mean value of the N-type doping is $[\mathrm{N}] \sim 3.5( \pm 2.2) \times 10^{16} \mathrm{~cm}^{-3}$ and of the Al-doping is $[\mathrm{Al}] \sim 6.3( \pm 3.5) \times 10^{15} \mathrm{~cm}^{-3}$ (table 2). In both samples in the parenthesis is given the fluctuation of the impurity concentration from point to point of the sample.

\section{Conclusions}

We have grown cubic SiC on four differently prepared substrates. The least area of desired polytype was on annealed and covered with silicon substrates. This was mostly due to the steps created on the substrate during annealing step, which enhance $6 \mathrm{H}-\mathrm{SiC}$ growth. Growth on as-received and re-polished samples give very similar results. The reason for that is a homoepitaxial growth of $6 \mathrm{H}-\mathrm{SiC}$ before the $3 \mathrm{C}-\mathrm{SiC}$ nucleation. The initial surface of the substrate has negligible influence on the nucleation of cubic polytype. Almost 100\% 3C-SiC could be obtained in homoepitaxial growth on a buffer layer grown by VLS. The step controlled growth is dominant instead of two-dimensional nucleation, this gives more control over the growth process and less twins appear. However, the material quality distanced from the twin boundaries as seen from XRD measurements is better if we grow 3C-SiC directly on the $6 \mathrm{H}-\mathrm{SiC}$ substrates. From the photoluminescence measurements we see that the mean impurity concentration for $\mathrm{N}$ $\left(\sim 3.4 \times 10^{16} \mathrm{~cm}^{-3}\right)$ and $\mathrm{Al}\left(\sim 4.5 \times 10^{15} \mathrm{~cm}^{-3}\right)$ is similar for homoepitaxially and heteroepitaxially grown samples, however, there is small fluctuations in doping from point to point. This was more noticeable for Al which led to a weak PL signature of Donor Acceptor Pairs, i.e. slight compensation. The typical defects in the layers, as expected and confirmed by the TEM investigation, are twin boundaries and 
stacking faults. The density of SF slightly away from TBs is the lowest in the layers grown directly on $6 \mathrm{H}-\mathrm{SiC}$ substrates $\left(8 \times 10^{3} \mathrm{~cm}^{-1}\right)$. Higher density of SF was in the homoepitaxial layers, grown on VLS buffer layer $\left(1 \times 10^{4} \mathrm{~cm}^{-1}\right)$. Also the density of SF in 3C-SiC layer grown by sublimation epitaxy on buffer layer was decreased, compared to VLS buffer layer $\left(3 \times 10^{4} \mathrm{~cm}^{-1}\right)$ itself. Besides, the density of SF away from the TBs in homoepitaxial and heteroepitaxial layers is below TEM detection limit $\left(1 \times 10^{3} \mathrm{~cm}^{-1}\right)$. Such a low SF density maybe acceptable for device fabrication and therefore growth of 3C-SiC by sublimation epitaxy on VLS buffer layer seems to be promising.

\section{Acknowledgement}

This work was supported by FP6 Marie Curie Action - Research and Training Network - MANSiC contract $N^{\circ} 035735$, Swedish Energy Agency and Ångpanneföreningen Research Foundation. Authors are also thankful NovaSiC for polishing SiC substrates.

\section{References}

[1] H. Matsunami, T. Kimoto, Materials Science and Engineering, R20 (1997) 125-166.

[2] S. Nishino, Y. Hazuki, H. Matsunami, T. Tanaka, J. Electrochem. Soc. 127 (1980) 2674.

[3] M. Tuominen, R. Yakimova, A. Vehanen, E. Janzen, Materials Science \& Engineering B, B57, 3, (1999) 228-233.

[4] M. Soueidan, G. Ferro, J. Dazord, Y. Monteil, G. Younes, J. Cryst. Growth 275 (2005) e1011-1016.

[5] M. Soueidan, G. Ferro, Adv. Funct. Mater. 16 (2006) 975.

[6] M. Syvajarvi, N. Sritirawasarn, R. Yakimova, Material Science Forum 556-557 (2007) 195-198.

[7] J. Camassel, S. Juillaguet, M. Zielinski, C. Balloud, Chem. Vap. Dep. 12 (2006) 549.

[8] J. A. Powell, J. B. Petit, J. H. Edgar, I. G. Jenkins, L. G. Matus, J. W. Yang, P. Pirouz, W. J. Choyke, L. Clemen, M. Yoganathan, Appl. Phys. Lett. 59 (3) (1991) 333-335.

[9] Z.Y. Xie, J.H. Edgar, B.K. Burkland, J.T. George, J. Chaudhuri, Journal of Crystal Growth 224 (2001) $235-243$.

[10] R. Vasiliauskas, M. Syväjärvi, M. Beshkova, R. Yakimova, Mater. Sci. Forum 615-617 (2009) 189192.

[11] L. Latu-Romain, D. Chaussende, P. Chaudouet, F. Robaut, G. Berthome, M. Pons, R. Madar, J. Cryst. Growth 275 (2005) 609.

[12] H.S. Kong, B.L. Jiang, J.T. Glass K.L. More, G.A. Rozganyi, J. Appl. Phys. 63 (8) (1988) $2645-$ 2650. 
[13] J. Palmour, H. Kong, R. Davis, J. Appl. Phys. 64 (1988) 2168.

[14] J. Eriksson, M.H. Weng, F. Roccaforte, F. Giannazzo, S. Leone, V. Raineri, Appl. Phys. Lett. 95 (2009) 081907.

[15] H.P. Iwata, U. Lindelfelt, S. Öberg, P.R. Briddon, Phys. Rev. B68 (2003) 113202.

[16] G. Melnychuk, Y. Koshka, M. S. Mazzola, J. L. Wyatt, Materials Science Forum 483-485 (2005) 105-108.

[17] G. Ferro, M. Soueidan, O. Kim-Hak, J. Dazord, F. Cauwet, B. Nsouli, Materials Science Forum 600-603 (2009) 195-198.

[18] X.R. Huang, M. Dudley, W. Cho, R.S. Okojie, P.G. Neudeck, Materials Science Forum 457-460 (2004) 157-162.

[19] M. Syväjärvi, R. Yakimova, M. Tuominen, A. Kakanakova-Georgieva, M.F. MacMillan, A. Henry, Q. Wahab, E. Janzén, J. Cryst. Growth 197 (1999) 155-162.

[20] H. Jacobson, J. Birch, R. Yakimova, M. Syväjärvi, J. P. Bergman, A. Ellison, T. Tuomi, E. Janzen, J. Appl. Phys. 91 (10) (2002) 6354-6360.

[21] M. Tuominen, R. Yakimova, A. Kakanakova-Georgieva, M.F. MacMillan, M. Syväjärvi, E. Janzen, Journal of Crystal Growth 193 (1-2) (1998)101-108.

[22] M. Kohyama, R. Yamamoto, Solid State Phenomena 37-38 (1994) 55-56.

[23] M. Marinova, A. Andreadou, J. W. Sun, J. Lorenzzi, A. Mantzari, G. Zoulis, N. Jegenyes, S. Juillaguet, V. Souliere, G. Ferro, J. Camassel, E.K. Polychroniadis, Mater. Sci. Forum, 679-680 (2011) 241-244.

[24] D. Hansen, M. Loboda, Silicon Carbide 2008 - Materials, Processing and Devices (2008) 23-31.

[25] L.L. Clemen, R.P. Devaty, M.F. MacMillan, M. Yoganathan, W.J. Choyke, D.J. Larkin, J.A. Powel, J.A. Edmond, H.S. Kong, Appl. Phys. Lett. 62 (23) (1993) 2953.

[26] J.P. Bergman, E. Janzén, W.J. Choyke, Phys. Stat. Sol. (b) 210 (1998) 407.

[27] D. Chaussende, F. Mercier, A. Boulle, F. Conchon, M. Soueidan, G. Ferro, A. Mantzari, A. Andreadou, E.K. Polychroniadis, C. Balloud, S. Juillaguet, J. Camassel, M. Pons, Journal of Crystal Growth 310 (2008) 976-981.

[28] W.J. Choyke, D.R. Hamilton, L. Patrick, Phys. Rev. 133 (4A) (1964) A1163. 
Tables:

Table 1. Comparison of the growth parameters for different samples.

\begin{tabular}{|c|c|c|c|c|c|}
\hline Substrate & $\begin{array}{l}\text { Growth } \\
\text { time, min }\end{array}$ & Temperature, ${ }^{\circ} \mathrm{C}$ & Thickness, $\mu \mathrm{m}$ & $\begin{array}{l}\text { Growth rate, } \\
\mu \mathrm{m} / \mathrm{h}\end{array}$ & $\begin{array}{l}3 \mathrm{C} \\
\text { coverage, } \%\end{array}$ \\
\hline 6H-SiC as-received & 30 & 1775 & $133^{\mathrm{a}}$ & 266 & 87 \\
\hline 6H-SiC re-polished & 30 & 1775 & 195 & 390 & 87 \\
\hline 6H-SiC annealed & 30 & 1775 & 100 & 200 & 45 \\
\hline VLS buffer layer & 30 & 1775 & 170 & 340 & 99 \\
\hline
\end{tabular}

${ }^{a}$ slightly smaller temperature gradient

Table 2. Characteristics of $3 \mathrm{C}-\mathrm{SiC}$ grown on $6 \mathrm{H}-\mathrm{SiC}$ and buffer layer.

\begin{tabular}{|c|c|c|c|c|c|c|}
\hline Substrate & $\begin{array}{l}\text { Doping N, } \\
\mathrm{cm}^{-3}\end{array}$ & $\begin{array}{l}\text { Doping Al, } \\
\mathrm{cm}^{-3}\end{array}$ & $\begin{array}{l}\text { Substrate } \\
\text { surface } \\
\text { RMS, nm }\end{array}$ & $\begin{array}{l}\text { Density of } \\
\text { triangular } \\
\text { features, } \mathrm{cm}^{-2}\end{array}$ & $\begin{array}{l}\text { FWHM, } \\
\text { arcsec }\end{array}$ & $\begin{array}{l}\text { SF density, } \\
\mathrm{cm}^{-1}\end{array}$ \\
\hline $\begin{array}{l}\text { As- } \\
\text { received } \\
6 \mathrm{H}-\mathrm{SiC}\end{array}$ & $\sim 3.5 \times 10^{16}$ & $\sim 6.3 \times 10^{15}$ & $2.6-2.8$ & $5 \times 10^{4}$ & 88 & $8 \times 10^{3}$ \\
\hline $\begin{array}{l}\text { VLS buffer } \\
\text { layer }\end{array}$ & $\sim 3.3 \times 10^{16}$ & $\sim 3.7 \times 10^{15}$ & $10 / 15 / 11$ & $2 \times 10^{5}$ & $116-700$ & $1 \times 10^{4}$ \\
\hline
\end{tabular}

